\title{
Test-Retest Reliability of the Speech, Spatial and Qualities of Hearing Scale (SSQ) in Brazilian Portuguese
}

\author{
Raiza Gorbachev Ribeiro Aguiar ${ }^{1} \quad$ Katia de Almeida ${ }^{1}$ \\ $1^{1}$ Faculty of Medical Sciences, School of Speech-Language Pathology \\ and Audiology, Santa Casa de São Paulo, São Paulo, SP, Brasil \\ Int Arch Otorhinolaryngol 2019;23:e380-e383.
}

\author{
Elisiane Crestani de Miranda-Gonsalez ${ }^{10}$
}

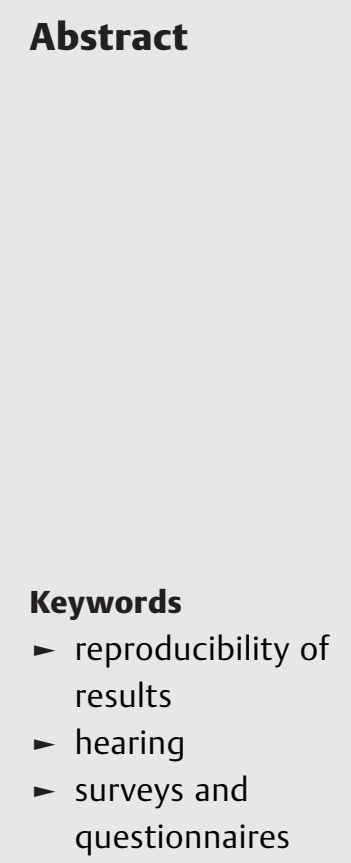

\begin{abstract}
Address for correspondence Elisiane Crestani de Miranda-Gonsalez, PhD, Escola de Fonoaudiologia e Audiologia, Faculdade de Ciências Médicas da Santa Casa de São Paulo, Rua Dr. Cesário Motta Júnior, 61; $10^{\circ}$ andar CEP: 01221-020, São Paulo, SP, Brasil (e-mail: elisiane.miranda@fcmsantacasasp.edu.br).
\end{abstract}

\section{Introduction}

The Speech, Spatial and Qualities of Hearing Scale (SSQ) is a questionnaire designed to assess auditory experience and quantify hearing disabilities in realistic communication situations, with particular attention to binaural hearing. The questionnaire explores the main aspects of hearing through 49 items organized into three domains measuring: the capacity of the individual to listen to speech in different hearing contexts (Part 1-Speech Hearing); localization of sound events for different directions, distances and movement (Part 2-Spatial Hearing); and the listening experience in relation to segregating sounds, musical perception, clarity and naturalness of sounds, and listening effort; (Part 3Qualities of Hearing). ${ }^{1}$

received

October 9, 2017

accepted

December 2, 2018
Introduction The Speech, Spatial and Qualities of Hearing Scale (SSQ) is a questionnaire designed to assess the auditory experience and quantify hearing disabilities in realistic communication situations, with particular attention to binaural hearing.

Objective To determine the test-retest reliability of the SSQ in Brazilian Portuguese. Method A total of 35 individuals with mean age of 61 years and mean education of 7 years were interviewed. The mean auditory threshold was $44.29 \mathrm{dBNA}$ in the best ear and 58.04 dBNA in the worst ear. The SSQ in Portuguese was applied at two time points, test and retest. An interval of 7 to 20 days between interviews was established. The level of significance adopted was 0.05 , or $5 \%$.

Results The analysis revealed a high Cronbach $\alpha$ coefficient for the three domains and for the general component of the scale, demonstrating good internal consistency between the items. In addition, a significant strong correlation was detected between test and retest of the SSQ on the analysis by domain and for the general component of the scale. A significant moderate-to-strong correlation between test and retest by question was found, except for question 2 of Part I.

Conclusion The test-retest reliability indicators showed good stability of the Portuguese version of the SSQ, indicating that the scale is suitable for use in the hearingimpaired population in Brazil. 
populations. Thus, to promote wider use of the Portuguese version of the SSQ the test-retest reliability of the scale must be investigated in hearing-impaired individuals.

Therefore, the objective of the present study was to determine the test-retest reliability of the Brazilian Portuguese version of the SSQ in adults with hearing loss.

\section{Method}

A prospective, clinical study was conducted at a teaching hospital following approval by the local Research Ethics Committee (Permit CEP $n^{\circ}$ 273.023). The participants were volunteers and gave consent for all procedures involved in the study.

The study sample included 35 individuals fluent in Brazilian Portuguese, without apparent intellectual deficits and with acquired hearing loss. The group comprised 21 women and 14 men with a mean age of 61 (SD 12.64) years and average education of 7 years (SD 3.42). The mean hearing thresholds, based on the frequencies $500 \mathrm{~Hz}$, $1 \mathrm{kHz}, 2 \mathrm{kHz}$ and $4 \mathrm{kHz}$, were $44.29 \mathrm{~dB}$ NA for the best ear and 58.04 dB NA for the worst ear. Of the participants, $71.4 \%$ exhibited sensorineural type and $28.6 \%$ mixed-type hearing loss, while there were no cases of conductive hearing loss. No significant differences in auditory thresholds were found between the best $(44.29 \mathrm{~dB})$ and worst (58.04 dB) ears.

The participants answered questions on aspects of their hearing and listening capacity and experience in different situations. The interviewer read each question out aloud, ensuring that the patients were able to hear and understand the questions. The participants rated their communication performance for each situation, assessed with a score of 0 to 10. It was explained to the subjects that 10 indicated they were able to perform the situation in the question perfectly, whereas 0 indicated they were completely unable to perform the situation. In addition, there was an option "not applicable" for cases in which the question did not represent an everyday situation for patients. The participants were then asked to explain why the question did not apply to them.

The Brazilian Portuguese version of the SSQ was applied by the same interviewer at two time points, called test $\left(1^{\text {st }}\right.$ interview) and retest ( $2^{\text {nd }}$ interview), with both applications made in the morning. The interval between assessments averaged 11 days.

The reproducibility of version 5.6 of the SSQ in Brazilian Portuguese was assessed using Spearman non-parametric correlation. The correlation determined by this statistical method denotes the degree of relationship between the test and retest of the scale in the range 0 to 1 . Internal consistency of the SSQ was measured by analyzing the mean correlations among items based on Cronbach $\alpha$ coefficient. A significance level of 0.05 , or $5 \%$, was adopted.

\section{Results}

The mean values for the two applications of the questionnaire differed only slightly.

The mean scores on the questionnaires showed a significant moderate-to-strong correlation between test and retest. No significant correlation was detected between test and retest for question 2 of Part I (-Tables 1, 2).

A significant strong correlation between test and retest of the SSQ was observed. The responses of the participants for the three domains showed high reliability, indicating that respondents provided similar answers at the two application time points ( $\mathbf{-}$-Table $\mathbf{3}$ ).

A significant strong correlation was found among all domains and for the 49 questions (-Table 4 ).

\section{Discussion}

The analysis of SSQ scores revealed a similar result to those reported in other studies in the literature for the hearingimpaired population. ${ }^{1,8}$ By contrast, normal-hearing individuals tend to have higher scores ranging from 7.1 to $9.4 .^{6,9-11}$ Previous studies have shown a decline in SSQ scores with increasing hearing thresholds by 0.43 to 0.69 points per $10 \mathrm{~dB}$ of hearing loss. ${ }^{8,12}$ These findings suggest that the use of this instrument can reveal the problems caused by hearing loss and screen individuals with or without hearing deficits.

A difference in performance was evident among the hearing domains assessed by the scale, with lower mean scores on the speech-related domain (Part I) than on the spatial (Part II) and qualities of hearing (part III) domains.

Table 1 Descriptive analysis of indicators for the three domains (Parts I, II and III) and general component of the SSQ at test and retest

\begin{tabular}{|c|c|c|c|c|c|c|}
\hline Application & SSQ & Mean & Median & SD & Minimum & Maximum \\
\hline \multirow[t]{4}{*}{ Test } & Part I & 4.12 & 4.00 & 0.32 & 0 & 10 \\
\hline & Part II & 4.92 & 5.00 & 0.26 & 0 & 10 \\
\hline & Part III & 5.98 & 6.50 & 0.25 & 0 & 10 \\
\hline & General & 5.01 & 4.65 & 0.04 & 0 & 10 \\
\hline \multirow[t]{4}{*}{ Retest } & Part I & 4.25 & 4.50 & 0.16 & 0 & 10 \\
\hline & Part II & 4.92 & 5.00 & 0.26 & 0 & 10 \\
\hline & Part III & 5.98 & 6.60 & 0.25 & 0 & 10 \\
\hline & General & 5.05 & 5.00 & 0.06 & 0 & 10 \\
\hline
\end{tabular}

Abbreviation: SD, standard deviation; SSQ, speech, spatial and qualities of hearing scale. 
e382 Test-Retest Reliability of the Speech, Spatial and Qualities Aguiar et al.

Table 2 Test-retest correlation by question on the Brazilian Portuguese version of the SSQ scale (Spearman correlation)

\begin{tabular}{|c|c|c|c|c|c|c|c|c|}
\hline \multicolumn{3}{|l|}{ Part I } & \multicolumn{3}{|l|}{ Part II } & \multicolumn{3}{|l|}{ Part III } \\
\hline Question & $r$ & $p$-value & Question & $r$ & $p$-value & Question & $r$ & $p$-value \\
\hline Q1 & 0.679 & 0.001 & Q1 & 0.777 & 0.001 & Q1 & 0.625 & 0.001 \\
\hline Q2 & 0.464 & 0.060 & Q2 & 0.684 & 0.001 & Q2 & 0.679 & 0.001 \\
\hline Q3 & 0.797 & 0.001 & Q3 & 0.839 & 0.001 & Q3 & 0.767 & 0.001 \\
\hline $\mathrm{Q} 4$ & 0.796 & 0.001 & $\mathrm{Q} 4$ & 0.670 & 0.001 & Q4 & 0.666 & 0.001 \\
\hline Q5 & 0.784 & 0.001 & Q5 & 0.871 & 0.001 & Q5 & 0.605 & 0.001 \\
\hline Q6 & 0.830 & 0.001 & Q6 & 0.773 & 0.001 & Q6 & 0.590 & 0.001 \\
\hline Q7 & 0.618 & 0.001 & Q7 & 0.832 & 0.001 & Q7 & 0.635 & 0.001 \\
\hline Q8 & 0.745 & 0.001 & Q8 & 0.721 & 0.001 & Q8 & 0.622 & 0.001 \\
\hline Q9 & 0.577 & 0.001 & Q9 & 0.731 & 0.001 & Q9 & 0.812 & 0.001 \\
\hline Q10 & 0.813 & 0.001 & Q10 & 0.806 & 0.001 & Q10 & 0.401 & 0.031 \\
\hline Q11 & 0.829 & 0.001 & Q11 & 0.835 & 0.001 & Q11 & 0.548 & 0.001 \\
\hline Q12 & 0.808 & 0.001 & Q12 & 0.744 & 0.001 & Q12 & 0.729 & 0.001 \\
\hline Q13 & 0.809 & 0.001 & Q13 & 0.799 & 0.001 & Q13 & 0.847 & 0.001 \\
\hline \multirow[t]{5}{*}{ Q14 } & 0.889 & 0.001 & Q14 & 0.541 & 0.001 & Q14 & 0.878 & 0.001 \\
\hline & & & Q15 & 0.705 & 0.001 & Q15 & 0.693 & 0.001 \\
\hline & & & Q16 & 0.644 & 0.001 & Q16 & 0.882 & 0.001 \\
\hline & & & Q17 & 0.771 & 0.001 & Q17 & 0.876 & 0.001 \\
\hline & & & & & & Q18 & 0.657 & 0.001 \\
\hline
\end{tabular}

Abbreviation: r, correlation; SSQ, speech, spatial and qualities of hearing scale.

Table 3 Spearman correlation for test-retest by domain and general component of the SSQ

\begin{tabular}{|l|l|l|c|}
\hline SSQ & No. of Items & Correlation & $p$-value \\
\hline Part I & 14 & 0.930 & $<0.001$ \\
\hline Part II & 17 & 0.913 & $<0.001$ \\
\hline Part III & 18 & 0.893 & $<0.001$ \\
\hline General & 49 & 0.932 & $<0.001$ \\
\hline
\end{tabular}

Abbreviations: Part I, speech hearing; Part II, spatial hearing; Part III, qualities of hearing; SSQ, speech, spatial and qualities of hearing scale.

Table 4 Cronbach $\alpha$ correlation by domain

\begin{tabular}{|l|l|l|c|}
\hline SSQ & No. of Items & Correlation & $p$-value \\
\hline Part I & 14 & 0.952 & $<0.001$ \\
\hline Part II & 17 & 0.945 & $<0.001$ \\
\hline Part III & 18 & 0.822 & $<0.001$ \\
\hline General & 49 & 0.932 & $<0.001$ \\
\hline
\end{tabular}

Abbreviations: Part I, speech hearing; Part II, spatial hearing; Part III, qualities of hearing; SSQ, speech, spatial and qualities of hearing scale.

Score disparities among the subscales may be useful for assessing specific aspects of hearing disability.

In the present study, a significant correlation was detected between the different items of the scale, with a high Cronbach $\alpha$ (0.932). The scales are self-report instruments susceptible to random errors inherent to subjective assessments. The lower the occurrence of such errors and the greater the stability of responses among items, the higher the accuracy of the measurements and, consequently, the greater the reliability of the instrument. Akin to results reported for normal-hearing subjects $(0.946),{ }^{6}$ the Brazilian Portuguese SSQ showed good internal consistency in the hearing-impaired population.

Two of the objectives of the present study were to examine the test-retest properties of the Brazilian Portuguese SSQ and to determine the reliability of the instrument. The results suggest that, for this sample, irrespective of the application time point, the responses did not differ significantly for the three domains and general component of the SSQ evidencing good stability for responses. Analysis of the mean response scores at test and retest by question (49 questions) revealed the occurrence of slight differences in answers. Of all questions, only question 2 of Part I failed to exhibit a significant correlation between test and retest, indicating greater variability in responses between applications. The word "acarpetado" in Brazilian Portuguese is believed to have attributed to the variation in answers on this question, given this vocabulary is not commonly used in Brazil.

Cognitive aspects, age and educational level need to be further investigated in Brazil, since these may influence the understanding of the questions and performance on the SSQ as previously reported in the international literature. ${ }^{1,13-16}$ 


\section{Conclusion}

The reliability indicators (test-retest and internal consistency) suggest good stability of the Portuguese version of the SSQ showing that the scale is suitable for use in the hearing-impaired population in Brazil.

\section{Note}

Study performed at the School of Speech-Language Pathology and Audiology and Professional Master's in Health for Human Communication at Faculdade de Ciências Médicas da Santa Casa São Paulo-São Paulo (SP), Brazil.

\section{Conflicts of Interest}

The authors have no conflicts of interest to report.

\section{References}

1 Gatehouse S, Noble W. The Speech, Spatial and Qualities of Hearing Scale (SSQ). Int J Audiol 2004;43(02):85-99

2 Galvin KL, Noble W. Adaptation of the speech, spatial, and qualities of hearing scale for use with children, parents, and teachers. Cochlear Implants Int 2013;14(03):135-41. doi: 10.1179/1754762812Y.0000 000014

3 Noble W, Gatehouse S. Effects of bilateral versus unilateral hearing aid fitting on abilities measured by the Speech, Spatial, and Qualities of Hearing Scale (SSQ). Int J Audiol 2006;45(03):172-181

4 Blamey PJ, Fiket HJ, Steele BR. Improving speech intelligibility in background noise with an adaptive directional microphone. J Am Acad Audiol 2006;17(07):519-530

5 Noble W, Tyler RS, Dunn CC, Bhullar N. Younger- and older-age adults with unilateral and bilateral cochlear implants: speech and spatial hearing self-ratings and performance. Otol Neurotol 2009; 30(07):921-929
6 Gonsalez ECM, Almeida K. Adaptação cultural do questionário Speech, Spatial and Qualities of Hearing Scale (SSQ) para o Português Brasileiro. Audiol Commun Res 2015;20(03):215-224

7 Guillemin F, Bombardier C, Beaton D. Cross-cultural adaptation of health-related quality of life measures: literature review and proposed guidelines. J Clin Epidemiol 1993;46(12):1417-1432

8 Vannson N, James C, Fraysse B, et al. Quality of life and auditory performance in adults with asymmetric hearing loss. Audiol Neurotol 2015;20(01, Suppl 1):38-43

9 Demeester K, Topsakal V, Hendrickx JJ, et al. Hearing disability measured by the speech, spatial, and qualities of hearing scale in clinically normal-hearing and hearing-impaired middle-aged persons, and disability screening by means of a reduced SSQ (the SSQ5). Ear Hear 2012;33(05):615-616

10 Singh G, Kathleen Pichora-Fuller M. Older adults\&\#x2019; performance on the speech, spatial, and qualities of hearing scale (SSQ): Test-retest reliability and a comparison of interview and self-administration methods. Int J Audiol 2010;49(10):733-740

11 Humes LE, Kidd GR, Lentz JJ. Auditory and cognitive factors underlying individual differences in aided speech-understanding among older adults. Front Syst Neurosci 2013;7:55-62

12 Moulin A, Pauzie A, Richard C. Validation of a French translation of the Speech, Spatial, and Qualities of Hearing Scale (SSQ) and comparison with other language versions. Int J Audiol 2015;54 (12):889-898

13 Akeroyd MA, Guy FH, Harrison DL, Suller SL. A factor analysis of the SSQ (Speech, Spatial, and Qualities of Hearing Scale). Int J Audiol 2014;53(02):101-114

14 Dwyer NY, Firszt JB, Reeder RM. Effects of unilateral input and mode of hearing in the better ear: self-reported performance using the speech, spatial and qualities of hearing scale. Ear Hear 2014;35(01):126-136

15 Potts LG, Litovsky RY. Transitioning from bimodal to bilateral cochlear implant listening: speech recognition and localization in four individuals. Am J Audiol 2014;23(01):79-92

16 Ramos IMPMV, Martins JHF, Silva CSDM. The speech, spatial and qualities of hearing scale - Tradução e adaptação cultural para o Português Europeu. Cad Otorrinolaringol 2014:1-7 